\title{
La Bienal de Música Contemporánea de 1964
}

\author{
The 1964 Biennial of Contemporary Music
}

\section{RESUMEN}

La celebración en Madrid de la Bienal de Música Contemporánea en 1964 supuso para sus organizadores romper con el aislamiento al que había estado sometida la música de vanguardia española: por un lado, ésta tomó contacto con las últimas obras y procedimientos compositivos europeos; por otro, se dio a conocer en los ambientes internacionales, que tantos años le habían estado vedados. Los cambios artísticos y culturales en la España franquista hicieron posible la celebración de un festival de estas características, patrocinado por el Estado y con la música contemporánea como protagonista. Pero esta iniciativa, que debía prolongarse en el tiempo con sucesivas ediciones, se frustró desde el momento en que la música se mezcló con la política. Apoyándose en fuentes hemerográficas y archivísticas, este artículo analiza el desarrollo de la Bienal y profundiza en las consecuencias artísticas, musicales y políticas que se derivaron de dicho evento.

Palabras clave: España; franquismo; música contemporánea; vanguardias; festivales.

\begin{abstract}
The Biennial of Contemporary Music, held in Madrid in 1964, represented the end of the Spanish avant-garde music's isolation. On the one hand, this music made contact with the most recent works of European composers; on the other, it made itself known abroad, after many difficulties. The last artistic and cultural changes in francoist Spain made possible a music event of this kind: a festival that spotlighted contemporary music and enjoyed official sponsorship. This effort, planned to be continued over time, was cancelled when music mixed with politics. By analysing newspaper and archival sources, this article examines the development of the Bienal and the artistic, music and political consequences resulting from it.
\end{abstract}

Key words: Spain, Francoism, contemporary music, vanguards, festivals.

San Llorente Pardo, I. (2017). La bienal de música contemporánea de 1964. Cuadernos de Investigación Musical, 3, 75-95.

doi: http://dx.doi.org/10.18239/invesmusic.v0i3.1699 


\section{INÉS SAN LLORENTE PARDO}

\section{INTRODUCCIÓN}

La década de 1960 significó para España un progreso económico sin precedentes. La mejora en los estándares de bienestar y el aumento del poder adquisitivo, que fueron posibles tras el cambio en la política económica, constituirían la principal fuente de legitimación empleada por el régimen en estos años (Gracia y Ruiz Carnicer, 2001: 127) ${ }^{1}$. Esta evolución tuvo su correlato en el ámbito cultural. La mayor capacidad de consumo incidió en las expectativas vitales de los españoles. Por otra parte, la llegada masiva de turistas - con nuevas costumbres, formas de vestir y usos sociales- y el impacto de los medios de comunicación de masas -especialmente la televisión- jugaron un importante papel en esta transformación. Pronto quedó claro, incluso para la alta jerarquía del franquismo, que la España del desarrollo "no podría contentarse con el oscurantismo informativo y cultural" que había caracterizado a los cuarenta y los cincuenta (Doval, 2007: 50). Por eso, la dictadura trató de adaptarse a los nuevos tiempos y promovió una "liberalización" cultural y artística diseñada para explotar en beneficio propio las nuevas perspectivas que ahora se abrían, con la intención de no perder el control sobre la sociedad (Quaggio, 2014: 45).

Una de las consecuencias más evidentes de esta política de apertura fue el protagonismo otorgado a la música española y, concretamente, a la de vanguardia ${ }^{2}$. Así, desde 1960 comenzó a prestarse un apoyo decidido a todo tipo de manifestaciones dentro de este campo: mientras se celebraba el Festival de Música Joven³ ${ }^{3}$ tuvo lugar en Madrid el primer concierto de Tiempo y Música ${ }^{4}$, en Barcelona apareció Música Abierta y el pianista David Tudor inició un ciclo de conciertos con obras de John Cage. Con la nueva década se iniciaba una época de auténtica "explosión para la nueva música", marcando un punto de no retorno en la evolución de la música española (Casares Rodicio, 1980: 80).

\footnotetext{
${ }^{1}$ A finales de los años cincuenta, el modelo económico de inspiración fascista que aún perduraba en España produjo una crisis económica de grandes dimensiones. Estas tensiones también se extrapolaron a la sociedad, donde una nueva oposición, alejada del exilio republicano, emergía de la mano de jóvenes estudiantes de izquierdas e intelectuales distanciados de los postulados franquistas. El régimen mutó en 1957 para hacer frente a estos retos económicos y sociales. Los tecnócratas -hombres de negocios, profesionales y técnicos formados en la Universidad y relacionados con el Opus Dei- entraron en el Gobierno y pusieron en marcha un programa que combinaba reformas en la Administración Pública y medidas de liberalización económica. En los sesenta se inició una limitada apertura que se puso de manifiesto en la relajación de la censura tras la promulgación de la Ley de Prensa e Imprenta de 1966. Vid. al respecto Soto Carmona (2005), Hispán Iglesias de Ussel (2006), Townson (2009) y Giménez Martínez (2014).

${ }^{2}$ Efectivamente, en los sesenta la música cobraría un protagonismo sin precedentes en el panorama nacional y, lo que es más importante, disfrutaría del mecenazgo oficial. En estos años se subvencionarían todo tipo de festivales, temporadas de ópera y representaciones de ballet, con el apoyo decidido del Ministerio de Información y Turismo durante la "era Fraga" (Medina, 1987: 381).

3 Organizado por Juventudes Musicales y Tiempo y Música. En él se estrenaron obras consideradas como "plenamente vanguardistas": Cinco Microformas de Cristóbal Halffter, Dos Epitafios de Mestres Quadreny, Cuatro Invenciones de Luis de Pablo y el Concierto para piano de Manuel Castillo.

${ }^{4}$ Esta iniciativa fue financiada por el Sindicato Español Universitario (SEU) y su principal promotor fue Luis de Pablo (2007: 24): "Una parte del SEU programaba actividades culturales: una revista llamada Acento, exposiciones y algún concierto que otro. [...] El caso es que conseguimos financiación para organizar algunos conciertos en el Teatro María Guerrero de Madrid bajo la denominación genérica de Tiempo y Música. El primero, en 1960, fue el estreno en España de las Improvisaciones sobre Mallarmé de Boulez; [...] se interpretó en España antes que en París".
} 


\section{La Bienal de Música Contemporánea de 1964}

El régimen franquista era consciente de los beneficios que el fomento de este arte experimental podría reportarle en sus relaciones internacionales, de la misma forma que ya había ocurrido con la vanguardia plástica en los años cincuenta. Es por ello que pudo iniciarse una tímida equiparación entre lo que se dio en llamar "el nivel subterráneo" -las vanguardias musicales- y "el nivel oficial" -el casticismo patrocinado por las autoridades-. Las manifestaciones más avanzadas, hasta entonces con escasa circulación, obtuvieron así un cierto reconocimiento del Estado y, sobre todo, de los medios extranjeros, ya que el público español se mostró todavía muy reticente (Pérez de Arteaga, 1977: 301).

Uno de los primeros síntomas de este cambio de tendencia en la vida musical se produjo en 1962, cuando el Premio Nacional de Música recayó en Carmelo Bernaola, representante de la incipiente vanguardia madrileña, quien logró el galardón gracias a Cuarteto $n^{0} 1$, de "clara superación tonal" (Iglesias, 1982: 69) ${ }^{5}$. Como señala Casares Rodicio (1987: 314), de la misma forma que el Premio Nacional dado en 1925 a la Sinfonietta de Ernesto Halffter había significado "una especie de confirmación [...] de la nueva estética" neoclasicista de los años veinte, el de 1962 era una señal, no menos importante, de reconocimiento a las formas de lenguaje experimental ${ }^{6}$.

A partir de entonces, el franquismo puso en marcha un programa de "normalización cultural" que pretendía impulsar la imagen de un Estado "moderno y actualizado", inalcanzable a través de su apariencia política. 1964, año en que la dictadura celebró los XXV Años de $\mathrm{Paz}^{7}$, fue especialmente prolífico en lo que a promoción de música de vanguardia se refiere. Las últimas corrientes musicales de Cristóbal Halffter y Luis de Pablo estuvieron presentes en actos oficiales tan significados como el Concierto de la Paz ${ }^{8}$, el I Festival de Música de América y España y la I Bienal de Música Contemporánea. Este último evento supuso la incorporación de la joven música española al contexto internacional europeo. No obstante, a pesar de los “avances más o menos decididos” (Gan Quesada, 2012: 170) de la nueva música, la vanguardia hubo de compartir escenario y cartel con prácticas y estéticas plenamente consolidadas.

\footnotetext{
${ }^{5}$ Con influencias del método dodecafónico de Schoenberg y los grandes clásicos del siglo XX como Bartók, Stravinskyy Hindemith, "pensado desde la abstracción musical como lenguaje y próximo a las técnicas seriales” (Gracia y Ruiz Carnicer, 2001: 372-373).

${ }^{6}$ Un mes antes, otra obra de Bernaola, Espacios variados, provocó un gran escándalo entre el público y la crítica musical. Los Premios Nacionales de Música habían abierto sus puertas de manera paulatina a varios representantes de la nueva generación: Cristóbal Halffter había sido premiado en 1953, Francisco Calés Otero en 1954 y Manuel Moreno Buendía en 1958.

7 Aguilar (2008: 189) considera los XXV Años de Paz "la mayor campaña propagandística del régimen en toda su historia". Cuidadosamente orquestada desde el poder, la operación fue deudora de los fastos fascistas que ritualizaban y sacralizaban la política. Su principal objetivo no fue otro que la justificación de la continuidad de la dictadura. Para ello, el régimen orientó todo su discurso hacia los logros y el desarrollo experimentados durante los últimos veinticinco años, especialmente en el ámbito económico, pero también en lo social y artístico.

${ }^{8}$ El Concierto de la Paz se celebró en Madrid el 16 de junio de 1964 y puede considerarse, junto a la Bienal, uno de los primeros espaldarazos oficiales a la música española de vanguardia. En el concierto se dieron cita obras de Cristóbal Halffter, Luis de Pablo, Ángel Arteaga y Miguel Alonso. Un análisis de este evento ha sido realizado por Contreras Zubillaga (2011).

${ }^{9}$ Para una aproximación a este evento y a sus consecuencias musicales, sociales y políticas, vid. Moro Vallina (2012).
} 


\section{INÉS SAN LLORENTE PARDo}

\section{GESTACIÓN DEL FESTIVAL}

La I Bienal de Música Contemporánea fue el último gran acontecimiento musical de 1964 y vino a institucionalizar una labor que ya había sido realizada con anterioridad en el campo de la música de vanguardia por otras entidades, como las Aulas de Música del Ateneo, el Servicio Nacional de Educación y Cultura, las Juventudes Musicales y los grupos Música Abierta y Tiempo y Música. Recordemos que estas asociaciones habían salvado a España del completo aislamiento en este ámbito, al abrirla a las prácticas musicales renovadas de Europa y América. Durante los años cincuenta y sesenta, los programas de concierto de todo el mundo se nutrieron con partituras adscritas a las tendencias más diversas y actuales: la Escuela de Viena, el serialismo integral de Boulez, la corriente concreta y electrónica de Eimert, Stockhausen o Ligeti y la música abierta de John Cage, entre otras. Estos movimientos llegaban a España en muy pequeñas dosis, con excesivo retraso y circunscritos, además, a Madrid y Barcelona, con lo que se condenaba a la "ignorancia musical" a gran parte de las provincias. Por otro lado, la actividad de estos grupos estaba condicionada por unos reducidos recursos económicos, lo que llevó a algunos de ellos a la desaparición ${ }^{10}$. A pesar de estos y otros esfuerzos, a la altura de 1963 el desconocimiento de la música de vanguardia era generalizado:

Uno de los muchos inconvenientes del aislamiento español es, sin duda, la falta de información en general, la carencia de medios para saber qué se hace y cómo, la desvinculación y el quehacer vivo y operante en los centros neurálgicos de lo cultural (De Pablo, 1963: 43).

A juicio de Luis de Pablo (1964a: 95), el principal objetivo que debía perseguir la música española era, de una vez por todas, conseguir unirse "a la del resto del mundo". Y ese sería, precisamente, el objetivo fijado para la I Bienal de Música Contemporánea.

Un año antes de su celebración apareció en Aulas $^{11}$ (1963a: 32) la primera mención al proyecto de crear un festival de música contemporánea que paliase la falta de "verdadero arraigo" de la nueva música en España y los frutos "siempre provisionales de la misma". Para ello, era necesario un festival de carácter oficial y permanente:

Se intenta la creación de un Festival -casi diríamos "el Festival"- que sirva, frente a Europa, de pantalla para la música española, entendiendo como tal la que de veras puede interesar a los círculos operantes europeos. [...] Resumiendo: el Servicio de Educación y Cultura anuncia su propósito para la próxima temporada de realizar un Festival Internacional de Música Contemporánea, con carácter al menos de bienal.

10 Tal fue el caso de Tiempo y Música y Música Abierta, creados en 1960 en Madrid y Barcelona, y cuyas actividades no llegaron más allá de 1964 y 1968, respectivamente. En el caso de Tiempo y Música la escasez de medios no permitió superar los tres conciertos anuales.

11 Revista cultural editada por el Servicio de Educación y Cultura de la Delegación Nacional de Organizaciones del Movimiento - encargado de poner en marcha la I Bienal-, dirigida por Félix María Ezquerra y cuyos colaboradores musicales eran Luis de Pablo, Manuel Yusta y Miguel Ángel Coria, entre otros. La publicación tuvo una vida corta, de 1963 a 1965. 


\section{LA BIENAL de Música CONTEMPoránEA DE 1964}

En este anuncio se señalaba el interés por crear un concurso como complemento del festival, de forma que los compositores ganadores del primero participaran en el segundo y contaran con una plataforma de lanzamiento en el panorama nacional e internacional. Para ello, el Servicio Nacional de Educación y Cultura creó ese mismo año un certamen de composición cuyo premio daba derecho al compositor al estreno de su obra en un concierto organizado dentro de la I Bienal de Música Contemporánea (Aulas, 1963b: 42). Esta primera edición la ganaría Antón García Abril con Homenaje a Miguel Hernández, cuyo estreno mundial tuvo lugar el 2 de diciembre de 1964 durante el cuarto concierto de la Bienal.

Igual que el I Festival de América y España, la Bienal tampoco se encontraba dentro de los actos conmemorativos de los XXV Años de Paz. Pero, como consecuencia de la "sobredosis" musical que había tenido lugar ese año ${ }^{12}$, la Bienal se presentaba de manera "coincidente" con el aniversario de la dictadura, quedando absorbida, quisiese o no, por el amplio espectro propagandístico de aquélla y exhibiéndose como otro de los frutos del desarrollo musical español: "una de las realizaciones más importantes de estos últimos veinticinco años" (Ritmo, 1964: 14). En esta línea, Enrique de la Hoz, como subdirector de Cultura Popular del Ministerio de Información y Turismo, en una recepción ofrecida al comienzo del festival para acoger a los representantes de los países extranjeros, declaraba que la I Bienal venía a cerrar "con gran brillantez" los acontecimientos musicales más importantes de aquel año 1964 (Franco, E., 1964a: 27).

Los balances triunfales esgrimidos por las autoridades del régimen chocaban con la inoperancia real de la política musical franquista en sus 25 años de vida, reconocida de forma casi unánime por los músicos españoles: "el triste retraso en que la música española se ha venido moviendo [...] es ya uno de los tópicos de la historia de nuestra cultura" (Ruiz Coca, 1965: 31). Desde su columna de Informaciones, Antonio Fernández-Cid se refería también a estos "años de silencio y abandono":

En este peregrino Madrid no tenemos términos medios, y luego de años de silencio y abandono en estos campos se nos ofrecen dosis triples, quizá -y sin quizá- excesivas para las apetencias de nuestros aficionados y de muchos profesionales que vuelven la espalda con extraño desprecio, desinterés o falta de conocimiento (Fernández-Cid, 1964a: 7).

Comentarios todos ellos que contrastan con otros que por su acentuado carácter propagandístico llegaban a sostener afirmaciones de este tenor: "En todo el mundo es conocido un hecho: España es uno de los países más interesados en la problemática y

\footnotetext{
${ }^{12}$ Hay que recordar, en cualquier caso, que Madrid se preparaba por entonces para celebrar en abril de 1965 el festival de la Sociedad Internacional de Música Contemporánea (SIMC), donde se darían cita de nuevo las corrientes musicales más actuales.
} 


\section{INÉS SAN LLORENTE PARDo}

realización de la nueva música" (Del Campo, 1964a: 24). Algo que no se correspondía con la realidad, puesta de manifiesto por algunos medios extranjeros:

Desde la creación del Concierto para violín de Alban Berg (Barcelona, 15 abril 1936), España tenía olvidados a los compositores de nuestros días. Se interpretaban, como en todas partes, obras de Brahms y Tchaikovsky; se añadía la inevitable nota folklórica con compositores sacados al azar de entre el neo-flamenco y el neo-romanticismo, pero de vanguardia... absolutamente nada. No es precisamente que estuviese proscrita, pero no se pensaba en ella y todo se desarrollaba como si Schoenberg y Webern no hubiesen existido. [...] Acaba de abrirse muy oficialmente en Madrid un festival de música moderna. No se trata de un pequeño festival para dar satisfacción a autores de segundo orden, sino un verdadero festival internacional siguiendo el modelo de Venecia, Varsovia o Donaueschinguen (Candide, 1964: 55) ${ }^{13}$.

La Bienal, que finalmente tuvo lugar entre el 28 de noviembre y el 7 de diciembre de 1964 en Madrid, estuvo organizada por el Servicio Nacional de Educación y Cultura del Movimiento a través de su Aula de Música, que por entonces dirigía Luis de Pablo. No solo llamaba la atención la contemporaneidad de las obras y los compositores que participarían en el evento sino el apoyo recibido: "De nuevo una entidad oficial se preocupa de la música infrecuente y patrocina un ciclo de imposible desarrollo en otro caso" (Fernández-Cid, 1964a: 7). Y es que, pocos años atrás, esto habría sido prácticamente impensable: “[...] nunca jamás pudo soñar una generación de compositores, no ya avanzados, sino resueltamente 'rompedores', tener tales facilidades, tales apoyos para el estreno, para la edición, para crear más o menos artificialmente un 'mercado”' (Sopeña, 1964a: 117).

La Comisión Ejecutiva del festival estaba formada por el director del Servicio Nacional de Educación y Cultura, Félix María Ezquerra (que actuó de presidente), Luis de Pablo (encargado de la organización y desarrollo del certamen), Manuel Yusta (que ejerció de secretario) y los críticos Federico Sopeña, Fernando Ruiz Coca y Enrique Franco (Salas Viu, 1965a: 33). También colaboraron los Ministerios de Información y Turismo -que prestaría su auditorio para las sesiones de inauguración y clausura-, Asuntos Exteriores y Educación Nacional, así como los agregados culturales de las embajadas de la República Federal de Alemania, Francia e Italia.

\section{DesarRollo de los ConCiertos}

El festival de música contemporánea se erigió como el mayor intento de integrar en el panorama europeo a la música española, al menos "desde el tiempo de Manuel de Falla", tras un período de incomunicación internacional a todos los niveles. En este sentido, eran

\footnotetext{
${ }^{13}$ La traducción al castellano de este artículo -escrito originalmente en francés- ha sido encontrada en el Archivo General de la Administración (AGA), Fondo (3) 49.09, Legajo 38679, Sig. Top. 23/54. El manejo de la prensa extranjera por los círculos de poder da cuenta del interés de las autoridades por conocer opiniones y críticas- sinceras que la censura impedía publicar en España.
}

Cuadernos de Investigación Musical, 2017, diciembre, $\mathrm{n}^{\circ}$ 3, págs. 75-95.

ISSN: 2530-6847

DOI: http://dx.doi.org/10.18239/invesmusic.v0i3.1699 


\section{La Bienal de Música ConTEMPoránEa de 1964}

varios los compositores y musicólogos que afirmaban que en España "existen conciertos" pero "no propiamente vida musical" (Aulas, 1963c: 48).

La escasa vigencia de lo compuesto tras Falla y el aislamiento de nuestro país han conseguido que la música española se haya encontrado ausente de las manifestaciones sonoras mundiales del último cuarto de siglo (Marco, 1964: 3).

Y es que, si la presencia de la música europea a este lado de los Pirineos había sido realmente escasa, no lo fue menos la de la de música española en Europa, lograda solo de forma aislada a través de algunos compositores como Pedro Espinosa, Cristóbal Halffter, Juan Hidalgo o Luis de Pablo, que habían intervenido recientemente en los festivales de Darmstadt y Donaueschingen ${ }^{14}$. Así, la Bienal estaba llamada a cumplir una misión de redescubrimiento de una realidad musical que "sistemáticamente le era ocultada" a los músicos y al público español y, al mismo tiempo, funcionar de escaparate para la generación "preparada y nada escasa" de compositores españoles que, "abandonando ya todo pintoresquismo", se habían adscrito a las últimas tendencias musicales europeas (Ruiz Coca, 1964a: 28). Esta ocasión pretendía ser, por tanto, la presentación oficial de la joven generación española ante Europa, como escasos meses antes se había mostrado ante el nuevo continente de la mano del I Festival de América y España. Sin embargo, en un medio internacional se señaló que, si en un principio el objetivo era "que los jóvenes compositores españoles se dirigieran a sus compatriotas y al mundo", el resultado final había sido el de "abrir a España a las nuevas ideas del mundo":

Los numerosos asistentes extranjeros -compositores, ejecutantes, críticos y teóricosfueron invitados, al parecer, no tanto para oír lo que se hace en España como para que España vea lo que se hace fuera (Salzman, 1965: 24) ${ }^{15}$.

La representación española en la Bienal correría a cargo, efectivamente, de los miembros de la Generación del 51. Aunque no todos sus integrantes se adscribían a las últimas corrientes vanguardistas (tal era el caso de Antón García Abril, cuya música se alineaba con la tradición formal y la armonía tonal), la mayoría de ellos encarnaban el lenguaje más actualizado de la música española: Miguel Ángel Coria, Cristóbal Halffter, Carmelo Alonso Bernaola, Juan Hidalgo y Luis de Pablo. Ciertos críticos, sin embargo, lamentaron la ausencia de autores catalanes como Joaquim Homs, José María Mestres

\footnotetext{
${ }^{14}$ Juan Hidalgo fue el primer español en participar en el Festival Internacional de Darmstadt, en 1957, con su obra Ukanga. Después le seguirían el pianista Pedro Espinosa, en 1958, y Luis de Pablo, en 1959. Fue allí donde De Pablo conoció a John Cage, David Tudor y otras personalidades que posteriormente participarían en la I Bienal de Música madrileña como Max Deutsch, Severino Gazzeloni y el Cuarteto Parrenín, entre otros. Por su parte, Cristóbal Halffter participaría en el Festival de Donaueschingen en 1963 con Sinfonía para tres grupos instrumentales.

${ }^{15}$ Hay traducción de este artículo en AGA, Fondo (3) 49.09, Legajo: 38669, Sig. Top. 23/54.
} 


\section{INÉS SAN LLORENTE PARDO}

Quadreny o Josep Cercós, que habían sido pioneros de algunas de aquellas inquietudes musicales (Fernández-Cid, 1964b: 7).

La representación europea, por su parte, estaba integrada por obras de Arnold Schoenberg, Anton Webern, Alban Berg, Olivier Messiaen, Karlheinz Stockhausen, Iannis Xenakis, Pierre Boulez, Luigi Nono, Luciano Berio, John Cage, Earle Brown y György Ligeti, entre otros. Además, el festival se propuso contar en cada edición con un invitado de reconocimiento internacional, pensando para esta primera ocasión en la presencia de Messiaen, Boulez o Stockhausen. El primero de ellos, además, daría una conferencia sobre "La ornitología y la música". Finalmente, y pese a ser confirmada su asistencia por algunos medios $^{16}$, ninguno de los tres compositores asistió al certamen, declinando la invitación en el último momento ${ }^{17}$. Aun así, la Bienal no quedó huérfana de figuras extranjeras del mundo de la música. Acudieron a Madrid, por ejemplo, Heinrich Strobel (presidente de la Sociedad Internacional de Música Contemporánea, director de la Radio de Baden-Baden y del Festival de Donaueschingen), Jack Bornoff (director del Consejo Nacional de Música de la UNESCO), Mario Labrocca (director del Festival de Venecia), Herbert Rübner (director de la radio de Hamburgo), y otros críticos y especialistas entre los que destacamos a Hans Heinz Stuckenschmidt (gran conocedor de la escuela de Viena), Heinz-Klaus Metzger (especialista en música aleatoria), Antoine Golea (especialista en Messiaen), Max Deutsch (alumno de Schoenberg y director de prestigio), Mario Bartolotto y Vicente Salas Viu (músico español exiliado en Chile) ${ }^{18}$.

La Bienal se completó con una serie de Conversaciones que giraron en torno al tema general de "Examen de las diversas corrientes estéticas en la composición actual", presididas por el infante José Eugenio de Baviera y Borbón, presidente de la Real Academia de Bellas Artes de San Fernando. En estas Conversaciones participaron cinco ponentes: el musicólogo y compositor español Manuel Valls, el crítico italiano Massimo Mila, el crítico y musicólogo alemán Stuckenschmidt (que finalmente tuvo que ser sustituido el día de su ponencia por Gerardo Gombau), el compositor y crítico español Vicente Salas Viu y el musicólogo francés Jean Etienne $\mathrm{Marie}^{19}$. Sin embargo, pese a su nombre, las Conversaciones no fueron verdaderos coloquios, sino intervenciones previamente fijadas de los ponentes sobre temas tratados desde un punto de vista individual, sin dar lugar a debate:

\footnotetext{
16 "Lo que sí es definitivo es la asistencia de Stockhausen, que será el invitado de este año. Es un propósito que cada Bienal tenga una figura de importancia como invitado” (Franco, J. M., 1964a: 31).

17 "Fue lamentable que no pudieran asistir Pierre Boulez ni Olivier Messiaen que, por circunstancias imprevisibles, se excusaron en el último momento" (Salas Viu, 1965: 34).

18 También se contaba con la presencia de Jesús Bal y Gay, músico y compositor gallego adscrito a la vanguardia que, como tantos otros, eligió México como lugar de exilio tras la Guerra Civil. Su viaje para asistir a la Bienal iba a ser el primero a España desde que se expatriase, pero se canceló en el último momento. No obstante, el músico regresaría al año siguiente para establecerse definitivamente en Madrid junto a su mujer, Rosa María Ascot, alumna de Enrique Granados y Manuel de Falla.

19 Las cinco ponencias respondían a los siguientes títulos: "Las grafías actuales: razones y problemas", "Significado general de la obra aleatoria", "La tímbrica como factor constructivo de la actual música", "Examen de las diversas proyecciones de la nueva música" y "Los modernos medios de difusión y su influencia dentro de la música de nuestro tiempo".
} 


\section{LA BIENAL de Música CONTEMPoránEA DE 1964}

Al no existir "conversación" y menos conversación polémica, no existió debate, con lo cual las sesiones pasaron a ser una fría exposición de puntos de vista, sin valor conclusivo (Valls, 1964: 29).

Dedicada con exclusividad a la música de vanguardia, la Bienal no iba dirigida, evidentemente, al público general, habida cuenta de la escasa adhesión a este tipo de música. La afluencia de público no fue una prioridad para los organizadores, que estaban centrados en romper los años de incomunicación. La aceptación, pensaban, vendría después con la "repetición del empeño":

No es cuestión de preguntarse si el público está preparado para ello o no (de hecho, una pequeña minoría sí lo está); [...] la preparación vendrá con la repetición del empeño; lo que sí resulta vital para la cultura musical española es que el aislacionismo no perdure (Marco, 1964: 2-3)20.

Aun así, la asistencia de compositores e intérpretes españoles fue realmente escasa, lo que dejaba entrever el desinterés que producía esta música entre los propios especialistas. Esto mismo resaltaba Antonio Fernández-Cid, un crítico que no se declaraba precisamente seguidor de tales tendencias:

Uno de los aspectos que más sorprende es la escasez de concurrencia profesional. ¡Qué poquísimos compositores, intérpretes! En realidad, ¿Es que Madrid no tiene más que ese puñado, esas docenas de personas interesadas en el quehacer y la evolución musical? Sin perjuicio, luego, de que pudiesen confesarse en las antípodas de obras que no es obligatorio admirar (Fernández-Cid, 1964c: 7).

La asistencia de público al festival quedó, en efecto, reducida a un grupo de compositores declarados afines a este tipo de música y marcada por la ausencia de aquellos otros que, considerando dichas corrientes lejos de sus gustos personales, no demostraron excesivo interés. No fue este el caso de los críticos que, más allá de sus preferencias, recogieron sin excepción en sus crónicas lo que pasaba en la Bienal ${ }^{21}$.

El festival contó con una amplia muestra de música que abarcaba desde los comienzos del siglo XX (con las Tres piezas para piano de Schoenberg, compuestas en 1908) hasta la actualidad de 1964; y con lenguajes que iban desde lo más "conservador", como

\footnotetext{
${ }^{20}$ Repetición imposible, pues la Bienal no volvería a organizarse.

${ }^{21} \mathrm{Y}$ eso a pesar de que el Ministerio de Información y Turismo había remitido invitaciones a la Sección Femenina, al Departamento de Actividades Culturales del SEU, al Instituto de Cultura Hispánica -para que fuesen repartidas entre alumnos y becarios hispanoamericanos-, al Conservatorio Superior de Madrid y a la Sección española de la Sociedad Internacional de Música Contemporánea, entre otros. AGA, Fondo (3) 49.12, Legajo: 44191, Sig. Top. 23/72.
} 


\section{INÉS SAN LLORENTE PARDO}

podía ser el Homenaje a Miguel Hernández de Antón García Abril, hasta los primeros ejemplos de pop-art de Gesti sulpiano, de Giuseppe Chiari:

Extraño cóctel de notas discordantes, la voz de Frank Sinatra en una grabación de película más un fragmento de Falstaff de Verdi superpuesto en la misma grabación, a lo que se adiciona en determinado momento el rasgar de un trozo de raso que el pianista cumple mientras descansa el teclado (Salas Viu, 1965a: 42).

Los conciertos tuvieron un "común denominador" que fue el constante estreno de obras: "más de treinta, para dar una cifra” (De Pablo, 1964a: 95). De hecho, la práctica totalidad de las audiciones de la Bienal constituyeron un estreno en España. Un lugar especial lo ocupó, por ejemplo, la obra de Schoenberg, coincidiendo con el nonagésimo aniversario de su nacimiento, con los estrenos de la Suite para siete instrumentos, op. 29 (1926) y la Oda a Napoleón (1944), dentro de un concierto-homenaje dirigido por el que fuera su alumno, Max Deutsch. Así, el compositor austriaco y su obra se seguían dando a conocer en España cuando habían pasado más de diez años de su muerte ${ }^{22}$. En el concierto de clausura se programaron también audiciones de sus más fieles discípulos, Alban Berg ${ }^{23}$ y Anton Webern, que coincidieron con el estreno de Atmosphères de Ligeti -estreno en España- y obras de los españoles Carmelo Alonso Bernaola (Espacios variados) y Luis de Pablo (Testimonio) ${ }^{24}$. Este concierto fue muy aplaudido por la posibilidad de escuchar la nueva música española "al nivel de los nombres más ilustres universales” (Ruiz Coca, 1964: 28).

El concierto reservado para la música española se celebró días antes, el 2 de diciembre de 1964. En él se dieron cita las obras de Miguel Ángel Coria (con un estreno absoluto, Vértices), Juan Hidalgo, Cristóbal Halffter y Antón García Abril; este último con la pieza ganadora del concurso del Servicio de Educación y Cultura, en la que el autor avanzaba "hacia una mayor radicalización de su lenguaje" (Sopeña, 1964c: 94). Pudieron escucharse, además, trabajos de Earle Brown y Luigi Nono. Si algo destacó la crítica de este concierto, y de la Bienal en su conjunto, fue la puesta al día de la música española, al menos en cuanto a esa minoría de compositores que podía al fin "dialogar con sencillez y facilidad con otros nombres y otras latitudes", algo que no ocurría "desde el Siglo de Oro" (Ruiz

\footnotetext{
22 Junto a la presentación de su obra, estaba teniendo lugar por entonces en España la traducción de los textos más importantes del compositor. En 1963, Ramón Barce había traducido El estilo y la idea, escrito en 1950 por el propio Schoenberg; Luis de Pablo, por su parte, tradujo en 1964 la biografía que Stuckenschmidt había escrito sobre el músico en 1951. Por último, el Tratado de Armonía, escrito en 1922, sería traducido más tarde por Ramón Barce, en 1974.

23 De forma paralela se programó el Concierto para violín de Alban Berg en el Palacio de la Música, interpretado por la Orquesta Nacional. Este constituyó, según Sopeña (1964b: 111), “un rotundo acierto de programación”, teniendo en cuenta lo infrecuente de su representación en España. 1964 sería igualmente el año en que se estrenase en nuestro país de forma íntegra la ópera Wozzeck (1922), de Alban Berg, el 30 de diciembre de 1964 en el Liceo de Barcelona. El estreno de Wozzeck en Madrid se produjo diez años más tarde, en 1974, en el Festival de Ópera correspondiente.

${ }^{24}$ Esta sería la segunda y última vez que la obra aparecería bajo el nombre de Testimonio. La primera había sido en el Concierto de la Paz. En lo sucesivo aparecería con el nombre de Tombeau. García del Busto, 1979: 58.
}

Cuadernos de Investigación Musical, 2017, diciembre, $\mathrm{n}^{\circ}$ 3, págs. 75-95.

ISSN: 2530-6847

DOI: http://dx.doi.org/10.18239/invesmusic.v0i3.1699 


\section{LA BIENAL de Música CONTEMPoránEA DE 1964}

Coca, 1965: 31). Fue en este concierto donde sonaron "los primeros bravos a la música contemporánea" (Del Campo, 1964b: 20) con una mención especial a Available Forms de Brown, una obra que incorporaba la aleatoriedad en la ejecución ${ }^{25}$. Otra de las revelaciones de este concierto fue su director, Enrique García Asensio, por entonces titular de la Orquesta Municipal de Valencia, que destacó por su "conocimiento y seguridad excepcionales" en el programa (De Pablo, 1964b: 81).

Pero no todo fueron cumplidos. El concierto integrado por obras de música abierta y experimental, celebrado el 5 de diciembre, cosechó críticas desfavorables. En él se escucharon la ya citada Gesti sul piano de Chiari, Klavierstück $X$ de Stockhausen (obra que acogió los mejores comentarios), Music of Changes IV de John Cage (donde se introduce la aleatoriedad en la composición con el uso del método de adivinación chino I Ching) y el piano preparado de Christian Wolff:

La mayoría tienen gran parecido de escritura, con los mismos procedimientos de salpicamiento de notas, pellizcado de cuerdas, golpes con la tapa del teclado, porrazos, etc. Y muy escaso - por no decir ninguno- valor estético ni musical. Oyendo la primera obra, que era de Cage, pensaba que mi nieta de cuatro años -que suele arremeter contra mi piano- es también compositor (Franco, J. M., 1964b: 36).

Por su parte, las Conversaciones desarrolladas de forma paralela a lo largo de los diez días de festival congregaron a "un total de treinta musicólogos extranjeros más un número semejante de compositores, críticos y musicólogos españoles" (Salas Viu, 1965a: 33-34). Entre la representación española fue notable la asistencia de músicos y críticos de provincias, frecuentemente marginados de la actividad musical desplegada en los dos grandes núcleos urbanos, Madrid y Barcelona: "El hecho de invitar a críticos de provincias, por lo inusitado, es lo suficientemente elogioso como para felicitar al organismo oficial que ha creado esta Bienal" (Aulas, 1965a: 41). Alrededor de estas Conversaciones se formularon diversas actuaciones para un mejor desenvolvimiento de la vida musical, algunas realmente ambiciosas, como la creación de una Comisión Internacional que coordinase todos los esfuerzos de musicólogos, compositores e intérpretes en favor de extender la música nueva, y otras -presuntamente- más asequibles, como la extensión de "la música en la educación secundaria y universitaria” y una "mayor atención general de la prensa, la radio y la televisión hacia la música" (Franco, E., 1964b: 23). Las ponencias e intervenciones debían ser recogidas posteriormente en un volumen cuya edición se canceló debido a la suspensión de las siguientes ediciones de la Bienal.

\footnotetext{
${ }^{25}$ La obra constaba de seis partituras numeradas y dispuestas alrededor del director, el propio Brown, compuestas para conjugar en cualquier caso unas con otras, ya que este último iba señalando, en el acto, su orden de ejecución.
} 


\section{INÉS SAN LLORENTE PARDo}

La Bienal fue retransmitida por radio, aunque no por televisión. En palabras de Federico Sopeña, esto último hubiese sido "excesivo", dado el carácter especializado de las obras, si bien la Oda a Napoleón de Schoenberg, bien lo merecía:

Nos alegramos de la transmisión por radio, directa o diferida, de casi todos los conciertos. [...] Comprendemos que televisarlos hubiera sido excesivo; pero no encontrar el cuarto de hora para algo tan de la pantalla, tan directo para el público como la Oda a Napoleón es grave fallo (Sopeña, 1964d: 95).

El festival fue de nuevo una ocasión para que se hicieran presentes viejos conocidos de la música española de preguerra, como el compositor madrileño Vicente Salas Viu, exiliado en Chile desde 1939. La Bienal fue para el músico su "primera intervención pública como "crítico"' en España (Letelier Llona, 1964: 6-7) , $^{26}$ con un papel destacado dentro del certamen, pues pronunció una conferencia ("Examen de las diversas proyecciones de la nueva música") y escribió un amplio artículo sobre el evento en la revista Aulas, publicado en el mes de enero de 1965. Es este un ejemplo más de la recuperación sistemática de figuras del panorama cultural y musical que intentó llevar a cabo el régimen: "Vicente Salas se ha incorporado a la Bienal y también -como fino madrileño- al andar pausado por nuestras calles o al vivir de nuestros ambientes" (Franco, E., 1964c: 24) ${ }^{27}$. Tras la Bienal, la presencia del compositor en España fue continuada. Al año siguiente, el músico participaría en unas conferencias celebradas en el Aula de Música del Ateneo sobre Tomás Luis de Victoria $(A B C, 1965: 75)$. Sin embargo, su paulatina incorporación a la vida musical española se truncaría debido a su temprana muerte, acaecida en $1967^{28}$.

Durante la celebración del festival, Salas Viu (1965b: 38-39), junto al resto de críticos y musicólogos extranjeros, alabó la labor incipiente de los jóvenes músicos españoles tras reconocer los años previos de difícil desarrollo musical:

Imagino muy bien, porque no estuve aquí, los años de desorientación y de angustia, de medular angustia, que debieron sucederse para un Cristóbal Halffter, Luis de Pablo,

\footnotetext{
${ }^{26}$ El músico, nacido en Madrid, había apoyado de forma temprana la causa republicana. Fue miembro de la Junta Central de la Música, en la que también participó Rodolfo Halffter, y su firma apareció en la Alianza de Intelectuales Antifascistas para la Defensa de la Cultura. Al estallar la guerra se alistó en la $47^{a}$ División del Ejército de la República, teniendo que exiliarse al término de la contienda. La de 1964 no era su primera visita a España. Ya antes "se le ofreció no solo un viaje para ir y venir sino para quedarse y continuar su trabajo allá”, aunque el músico prefirió mantener su residencia en el extranjero. Sobre este compositor, Marta Nieto Calleja está realizando una tesis doctoral dirigida por el profesor de la Universidad de Castilla-La Mancha Juan José Pastor Comín.

${ }^{27}$ Llama la atención cómo algunos críticos (Espinós Orlando, 1964a: 8) obviaban la nacionalidad española del músico y se referían a él como el "crítico chileno don Vicente Salas Viu".

28 Sopeña (1967: 652) señalaría que, de haber vivido más tiempo, Salas Viu habría acabado "por asentarse aquí", en España, pese a saber "cómo todavía es difícil para el español el diálogo, la convivencia, el liberalismo de fondo, la religiosidad como comprensión".
}

Cuadernos de Investigación Musical, 2017, diciembre, $\mathrm{n}^{\circ}$ 3, págs. 75-95.

ISSN: 2530-6847

DOI: http://dx.doi.org/10.18239/invesmusic.v0i3.1699 


\section{La Bienal de Música ConTEMPoránEa de 1964}

Carmelo Alonso Bernaola, Ramón Barce y todos los demás, estando por entonces como estaba España, la cultura musical española, y ellos mismos encerrados en sí mismos.

Por su parte, los medios internacionales aprovecharon para poner en evidencia el carácter conservador de la música española durante la primera mitad del siglo: "La música española del siglo XX, muy influida por Falla, ha sido tan conservadora como lo es el gusto del público" (Salzman, 1965: 24). Una situación que parecía cambiar con la actitud firme de compositores jóvenes como Halffter y De Pablo, que, no solo a través de su obra, sino también de su actividad en organismos oficiales, estaban dando un giro a esa situación de retraso musical en España:

Ahora, de repente, todo parece cambiar. Un compositor de talento, Cristóbal Halffter, de 34 años, -lo suficientemente avanzado como para describirlo de vanguardiaacaba de ser nombrado director del Conservatorio de Madrid. A otro joven modernista, Luis de Pablo, se le ha confiado -al menos en gran parte- la organización de una serie de conciertos y coloquios que de un solo golpe han situado a España en la segunda mitad del siglo XX musical. [...] No cabe dudar ya de que la España joven está con ellos (Salzman, 1965: 24$)^{29}$.

Resultaba fundamental que la actividad de la Bienal se prolongase en el tiempo "para bien de Madrid y de España" y solventar así que "un concierto formado enteramente con composiciones de Schoenberg sea todo en él estreno" (Marco, 1965: 46-48). Al término del festival, el director Félix Ezquerra anunció la celebración de la II Bienal para 1966, manifestando el deseo de que fueran muchos más los participantes europeos y americanos "que en dicha fecha nos visiten" (Espinós Orlando, 1964b: 8). Pero la Bienal, que como todo festival trajo consigo pequeños problemas de organización, no volvería a realizarse. Aunque desde los ambientes próximos al régimen relacionaron estos problemas técnicos con la cancelación del certamen, diversos medios hablaron de su "politización", después de que los comentaristas extranjeros aprovechasen la ocasión para dar una imagen de la España oficial "no grata a los ojos de la clase política" (García del Busto, 1979: 58).

Tomás Marco, por ejemplo, cita como causas de la cancelación de la Bienal "un mar de deudas y una catastrófica organización” (Marco, 1970: 39). Sin embargo, un repaso por los comentarios de prensa revela que los problemas organizativos no dejaron de significar peros irrelevantes: "poca puntualidad en los comienzos, pérdida de muchos minutos para solo mover un piano por falta de previsión" (Fernández-Cid, 1964d: 7) o "falta de publicidad, pequeñas improvisaciones y descuidos en las notas de los programas" (Sopeña, 1964d: 95). También se hacía mención a la deficiente educación musical no solo del público

\footnotetext{
${ }^{29}$ En el caso de Luis de Pablo, se refiere a su puesto de dirección del Aula de Música del Servicio Nacional de Educación y Cultura. Desde otro medio internacional (Candide, 1964: 55), se señalaba que la Bienal había permitido recorrer "en diez días" el camino que los "habituados de Venecia o Donaueschinguen han tardado veinte años en reconocer” y lo calificaba de “estupenda realización”.
} 


\section{INÉS SAN LLORENTE PARDo}

sino de los ejecutantes, lo que había dado lugar en algunas sesiones a una "pobre interpretación". Pero, en conjunto, "fue un gran esfuerzo, llevado a cabo con notable talento, soberbia organización" y "un propósito serio y bien dirigido" (Salzman, 1965: 24). Para Luis de Pablo, el motivo de que no volviera a celebrarse la Bienal estaba claro:

El régimen de Franco me pidió que diera luz a un encuentro dedicado a la música de vanguardia y yo acepté. En aquella época yo ya tenía amistad con importantes críticos de la época (entre ellos el ilustre "schoenbergiano" Hans Heinz Stuckenschmidt). Era la primera vez que visitaban España personalidades de aquel calibre y yo advertí a las autoridades de que iban a hablar de política. Entonces el régimen, que no entendía nada, me dijo: " ¿Y por qué razón van a hablar de política en lugar de música?”. Al final pasó lo que tenía que pasar. Vinieron, hablaron de música y política y una de las reseñas que se publicó en Italia sobre la Bienal se tituló "La música tras los falangistas". Eliminaron la Bienal inmediatamente y a mí con ella (El Correo de Andalucía, 2010: 45).

El artículo a que hace referencia De Pablo fue publicado por Massimo Mila ${ }^{30}$ en el periódico italiano L'Espresso con el título “Schönberg tra i falangisti”. En él, tras comentar la importancia de la promoción de la música de vanguardia en España, Mila destacaba la peculiar naturaleza de un "grupo de fascistas" -en referencia expresa al Estado españolque celebraban a Schoenberg (Sacau-Ferreira, 2010: 53).

Los resultados del evento quedaron, en definitiva, empañados, no solo porque no hubiera una II Bienal, sino porque dentro de la lógica del capitalismo tecnocrático en auge, la música no era rentable y, como consecuencia, en los años posteriores se terminó con las actividades que patrocinaba el Servicio Nacional de Educación y Cultura (Casares Rodicio, 1980: 108) ${ }^{31}$. En cuanto a Luis de Pablo, su biógrafo (García del Busto, 1979: 58) comenta que sobre él cayeron "ciertos aires de culpabilidad". Lo cierto es que su presencia se mantuvo en la mayoría de festivales oficiales organizados en los años posteriores: el Festival Internacional de la SIMC celebrado en Madrid en 1965, el II y III Festival de América y España (1967 y 1970), y diversos encargos de Radiotelevisión Española.

\section{ConClusiones}

La Bienal de Música Contemporánea supuso el primer intento oficial por promocionar la música de vanguardia española y a sus autores en el contexto europeo. La dictadura de Franco ambicionaba un cambio de imagen y la música de vanguardia se convirtió en un instrumento útil para alcanzar dicho fin. Así lo advirtió la prensa internacional e, incluso, los controlados medios nacionales. Sin embargo, el régimen no pudo evitar que desde el exterior se viese con cierto escepticismo este cambio de rumbo en

\footnotetext{
30 Massimo Mila, crítico y musicólogo italiano, era conocido por su oposición al régimen fascista italiano, lo que le valió no pocas estancias en prisión durante la época de Mussolini.

31 No todas, en realidad, puesto que siguió en funcionamiento la orquesta de cámara a través del Aula de Música del Servicio Nacional de Educación y Cultura, cuyo primer concierto tuvo lugar el 10 de octubre de 1964, dirigido por Benito Lauret (Aulas, 1965b: 2-3).
} 


\section{La Bienal de Música ConTEMPoránEa de 1964}

la política cultural de España, poniéndose de manifiesto lo incoherente de promocionar unas corrientes artísticas que habían sido tachadas en años anteriores de "extranjerizantes" y "antiespañolas". Ante el peligro de "contagio" de estas críticas al ámbito político, el Gobierno recurrió a la censura. Y así ocurrió que un movimiento dirigido desde las altas esferas para la "puesta al día" de la música fue frenado por las mismas instancias que lo habían impulsado. Este hecho paradójico sirvió para demostrar lo superficial de la voluntad de cambio del régimen y, sobre todo, lo irreconciliable de unos discursos artísticos y políticos que -a pesar de los esfuerzos- resultaban de todo punto incompatibles.

Pese a las dificultades, el régimen no dejaría de promocionar la música más actual mientras le resultase rentable, una política que benefició a ciertos compositores, quienes se vieron favorecidos en estos años y llegaron a ocupar puestos relevantes en las instituciones musicales españolas. La Bienal contribuyó a una suerte de "colaboracionismo" que ha dado lugar a debates interesados que no tienen en cuenta un hecho fundamental: la prioridad de estos compositores -más allá de su posicionamiento político- no fue otra que demostrar que la música de vanguardia era rentable y necesaria, aunque para ello hubieran de servir a los intereses del Estado franquista. Se trataba de un "mal necesario" para garantizar la continuidad de estas manifestaciones a través de la promoción de compositores y certámenes. Por eso pudo celebrarse, un año más tarde, el Festival de la SIMC, o las diferentes ediciones del Festival de América y España (1964, 1967 y 1970). La Bienal puso las bases, en definitiva, para una actualización musical que, si bien no careció de avances y retrocesos, fue pieza fundamental dentro de la vasta política de imagen del franquismo, dirigida a situar la cultura como uno de los ejes principales sobre los que construir la España del desarrollo.

\section{Programa de la Bienal de Música Contemporánea}

*Estreno en España

**Estreno mundial

Sábado, 28 de noviembre de 1964. $19.30 \mathrm{~h}$

Auditorio del Ministerio de Información y Turismo

Concierto de la Orquesta Nacional de España

Director: MAURICE LE ROUX

I

Cinco Piezas, op. 10 (1913), Anton Webern

*Chronochromie (1961), Olivier Messiaen

II

*Metástasis (1955), Iannis Xenakis

Jeux (1913), Claude Debussy

Lunes, 30 de noviembre de 1964. 19:30 h

Cuadernos de Investigación Musical, 2017, diciembre, $\mathrm{n}^{\circ}$ 3, págs. 75-95.

ISSN: 2530-6847 


\section{INÉS SAN LLORENTE PARDo}

Salón de Actos del Instituto Nacional de Previsión

Cuarteto Parrenín

Jacques Parrenin y Marcel Charpentier (violines)

Denes Marton (viola)

Pierre Penassou (violoncello)

I

*Cuarteto (1955), Bruno Maderna

*10 Sketches for string quartet (1940), Nikos Skalkottas

II

*Secuencias (1963), Mauricio Ohana

III

*Cuarteto (1961), Toshiro Mayuzumi

*Livre pour quartuor (II) (1950), Pierre Boulez

\section{Martes, 1 de diciembre de 1964. 19:30 h}

Salón de Actos del Instituto Nacional de Previsión

Homenaje a Arnold Schoenberg. XC Aniversario de su muerte

Grupo de Grandes Conciertos de la Sorbona

Director: MAX DEUTSCH

Colette Herzog (soprano)

John Riley (bajo)

Luciennne Dumonty Anne-Marie de la Villeon (piano)

Marcel Naulais (requinto)

Guy Deplus (clarinete)

Guy Arnaud (clarinete bajo)

Jacques Parrenin y Marcel Charpentier (violines)

Denes Marton (viola)

Pierre Penassou (violoncello)

\section{I}

* Suite para siete instrumentos op. 29 (1926)

Los jardines colgantes, op. 15 (1909)

II

Dos piezas para piano op. 33 (1932)

Tres piezas para piano op. 11 (1908)

*Oda a Napoleón op. 41 (1944)

\section{Miércoles, 2 de diciembre de 1964. 19:30 h}

Salón de Actos del Instituto Nacional de Previsión

Conjunto de Cámara del Ateneo

Director: ENRIQUE GARCÍA ASENSIO

Luis Villarejo (baritono)

\section{I}

**Vértices (1964), Miguel Ángel Coria

Caurga (1958), Juan Hidalgo

Espejos (1963), Cristóbal Halffter 


\section{La Bienal de Música CoNTEMPoránEA DE 1964}

**Homenaje a Miguel Hernández. (1964), Antón García Abril II

* Available forms I (1961), Earle Brown

* Polifonía, Monodía, Rítmica (1961), Luigi Nono

Jueves, 3 de diciembre de 1964. 19:30 h

Salón de Actos del Instituto Nacional de Previsión

Recital de flauta de Severino Gazzelloni

Frederick Rzewski (piano)

Julio Magro (percusión)

\section{I}

*Pieza para flauta y piano (1964), Andras Szöllösy

*Ekagra, para flauta en sol y piano (1964), Kazuo Fukushima

* Mei, para flauta sola (1961), Kazuo Fukushima

*Pour Flûte et piano (1963), Wlodzimierz Kotonski

II

* Sequenza, para flauta sola (1958), Luciano Berio

* Gymel (1960), Niccòlo Castiglioni

* Le merle noir, para flauta y piano (1944), Olivier Messiaen

Recíproco, para piccolo, flauta, flauta en sol, flauta en jazz, piano y percusión (1963), Luis de Pablo

\section{Sábado, 5 de diciembre de 1964. 19:30 h}

Salón de Actos del Instituto Nacional de Previsión

Recital de Piano por Frederick Rzewski

I

*Music of Changers IV (1951), John Cage

*Poem (1959), Frederick Rzewski

*Klavierstück X (1961), Karlheinz Stockhausen

II

*For piano with preparations (1957), Christian Wolff

*Extensions 3 (1952), Morton Feldman

*The Devil's Trill (1963), Rudolf Komorous

*Gesti sul piano (1962) Giuseppe Chiari

* Septenary (1964), Michael von Biel

\section{Lunes, 7 de diciembre de 1964. 19:30 h}

Auditorio del Ministerio de Información y Turismo

Concierto de la Orquesta Nacional de España

Director: BENITO LAURET

Carla Henius (soprano)

\section{I}

* Seis piezas op. 6 (1909), Anton Webern

*Lieder op. 22 (1915), Arnold Schoenberg

* Altenberg Lieder op. 4 (1912), Alban Berg

II 


\section{INÉS SAN LLORENTE PARDo}

*Atmosphères (1962), György Ligeti

Espacios Variados (1962), Carmelo A. Bernaola

Testimonio (1963), Luis de Pablo

\section{BIBLIOGRAFÍA}

$A B C$ (1965). "Conferencia con ilustraciones musicales en el Ateneo”, 6 de febrero, p. 75.

Aguilar, P. (2008). Políticas de la memoria y memorias de la politica. El caso español en perspectiva comparada. Madrid: Alianza.

Aulas (1963a). "Un festival y un concurso", n 4, pp. 32-33.

Aulas (1963b). "Bases para un concurso de composición”, n 5, pp. 42-43.

Aulas (1963c). "Entrevista con Manuel Valls", no 10, pp. 48-50.

Aulas (1965a). "La crítica ha dicho", n 23, pp. 41-42.

Aulas (1965b). "Seis meses de actividades. Orquesta de cuerda del Aula de Música", no 2425, pp. 2-3.

Candide (1964). "Franco a donné son visa", 10 de diciembre, p. 55.

Casares Rodicio, E. (1980). Cristóbal Halffter. Gijón: Universidad de Oviedo.

Casares Rodicio, E. (1987). “La música española hasta 1939, o la restauración musical”. En

E. Casares, I. Fernández de la Cuesta y J. López-Calo, Actas del Congreso Internacional "España en la música de Occidente”, vol. 2, pp. 261-322. Madrid: Ministerio de CulturaInstituto Nacional de las Artes Escénicas y de la Música.

Contreras Zubillaga, I. (2011). "El Concierto de la Paz: tres encargos estatales para celebrar el 25 aniversario del franquismo", Seminario de Historia, Universidad Complutense de Madrid, 24 de febrero.

De Pablo, L. (1963). "Carta abierta a los seguidores de Tiempo y Música". Aulas, no 5, 1963, pp. 43-44.

De Pablo, L. (1964a). "La Primera Bienal Internacional de Música Contemporánea". Triunfo, no 133 , pp. 95-97.

De Pablo, L. (1964b). "Primera Bienal Internacional (II)". Triunfo, no 134, p. 81.

De Pablo, L. (2007). A contratiempo. Madrid: Círculo de Bellas Artes.

Del Campo, A. (1964a). "I Bienal de Música Contemporánea". Pueblo, 1 de diciembre, p. 24.

Del Campo, A. (1964b). “I Bienal de Música Contemporánea”. Pueblo, 5 de diciembre, p. 20.

Doval, G. (2007). Los últimos años del franquismo (1969-1975). Madrid: Síntesis. 


\section{La Bienal de Música ConTEMPoránEa de 1964}

El Correo de Andalucía (2010). Entrevista a Luis de Pablo: "Cristóbal Halffter y yo somos como el agua y aceite", 9 de diciembre, pp. 45-46.

Espinós Orlando, J. (1964a). “Estrenos de García Abril, Coria, Brown y Nono”. Madrid, 5 de diciembre, p. 8.

Espinós Orlando, J. (1964b). "Lauret, Carla Henius y la Nacional clausuran los conciertos de la primera Bienal de Música Contemporánea”. Madrid, 10 de diciembre, p. 8

Fernández-Cid, A. (1964a). "I Bienal de Música Contemporánea”. Informaciones, 30 de octubre, p. 7.

Fernández-Cid, A. (1964b). "El eco de la I Bienal de Música Contemporánea". Informaciones, 11 de diciembre, p. 7.

Fernández-Cid, A. (1964c). "I Bienal de Música Contemporânea". Informaciones, 1 de diciembre, p. 7.

Fernández-Cid, A. (1964d). "I Bienal de Música Contemporánea". Informaciones, 2 de diciembre, p. 7.

Franco, E. (1964a). "Homenaje a Schoenberg por el grupo de conciertos de la Sorbona". Arriba, 3 de diciembre, p. 27.

Franco, E. (1964b). "Conversaciones sobre las diversas corrientes estéticas en la composición actual”. Arriba, 11 de diciembre, p. 23.

Franco, E. (1964c). "Recital del flautista Gazzeloni”. Arriba, 5 de diciembre, p. 24.

Franco, J. M. (1964a). "Primera Bienal de Música Contemporánea”. Ya, 1 de febrero, p. 31.

Franco, J. M. (1964b). "Música contemporánea para piano”. Ya, 10 de diciembre, p. 36.

Gan Quesada, G. (2012). “A la altura de las circunstancias. Continuidad y pautas de renovación de la música española”. En A. González Lapuente (ed.), Historia de la música en España e Hispanoamérica, vol. 7, pp. 169-231. Madrid: Fondo de Cultura Económica.

García del Busto, J. L. (1979). Luis de Pablo. Madrid: Espasa-Calpe.

Gracia, J. y Ruiz Carnicer, M. A. (2001). La España de Franco (1939-1975). Cultura y vida cotidiana. Madrid: Síntesis.

Giménez Martínez, M. A. (2014). El Estado franquista. Fundamentos ideológicos, bases legales y sistema institucional. Madrid: Centro de Estudios Políticos y Constitucionales.

Hispán Iglesias de Ussel, P. (2006). La política en el régimen de Franco entre 1957 y 1969. Proyectos, conflictos y luchas por el poder. Madrid: Centro de Estudios Políticos y Constitucionales. 


\section{INÉs SAN LLORENTE PARDo}

Iglesias, A. (1982). Bernaola. Madrid: Espasa-Calpe.

Letelier Llona, A. (1967). "Vicente Salas Viu”. Revista Musical Chilena, vol. 21, n 102, pp. 67.

Quaggio, G. (2014). La cultura en transición. Reconciliación y politica cultural en España, 19761986. Madrid: Alianza.

Marco, T. (1964). "Impacto de una bienal". Aulas, no 21, pp. 2-3.

Marco, T. (1965). "Entrevistas a Earle Brown y Massimo Mila". Aulas, n 23, pp. 46-48.

Marco, T. (1970). Música española de vanguardia. Madrid: Guadarrama.

Medina, A. (1987). "Primeras oleadas vanguardistas en el área de Madrid”. En E. Casares, I. Fernández de la Cuesta y J. López-Calo, Actas del Congreso Internacional "España en la música de Occidente”, vol. 2, pp. 369-398. Madrid: Ministerio de Cultura-Instituto Nacional de las Artes Escénicas y de la Música.

Moro Vallina, D. (2012). "El Festival de Música de América y España (1964-1970). Intercambios musicales entre las dos orillas". Cuadernos de Música Iberoamericana, vol. 24, pp. $143-173$.

Pérez de Arteaga, J. L. (1977). "La saga de la supervivencia: ocho lustros de vida musical". En Equipo Reseña, La cultura española durante el franquismo, pp. 297-307. Bilbao: Mensajero.

Ritmo (1964). "I Bienal de Música Contemporánea”, no 349, pp. 14-15.

Ruiz Coca, F. (1964a). "Inauguración de la I Bienal de Música Contemporánea”. El Alcázar, 1 de diciembre, p. 28.

Ruiz Coca, F. (1964b). "La Orquesta Nacional, con Carla Henius y Lauret, clausuran los conciertos de la Bienal”. El Alcázar, 9 de diciembre, p. 28.

Ruiz Coca, F. (1965). "La I Bienal Internacional de Música Contemporánea”. La Estafeta Literaria, $\mathrm{n}^{\circ} 308$, p. 31.

Sacau-Ferreira, Enrique (2010). Performing a political shift: avant-garde music in Cold War Spain (Tesis doctoral). Oxford: Oxford University.

Salas Viu, V. (1965a). "La Bienal Internacional de Música Contemporánea en Madrid”. Revista Musical Chilena, vol. 19, no 92, pp. 32-43.

Salas Viu, V. (1965b). "Una experiencia de la Bienal de Música Contemporánea”. Aulas, no 23, pp. 38-39.

Salzman, E. (1965). “Americans in Spain”. New York Herald Tribune, 31 de enero, p. 24.

Sopeña, F. (1964a). "Comienza la primera Bienal de música contemporánea”. ABC, 29 de noviembre, p. 117. 


\section{LA BIENAL DE Música CONTEMPORÁNEA DE 1964}

Sopeña, F. (1964b). "La Orquesta Nacional en el Palacio de la Música". ABC, 5 de diciembre, p. 111.

Sopeña, F. (1964c). "Estrenos españoles en la Bienal”. $A B C, 4$ de diciembre, p. 94.

Sopeña, F. (1964d). "Clausura de la Bienal”. $A B C, 10$ de diciembre, p. 95.

Sopeña, F. (1967). "Vicente Salas Viu”, Cuadernos Hispanoamericanos, no 216, pp. 650-652.

Soto Carmona, A. (2005). ¿Atado y bien atado? Institucionalización y crisis del franquismo. Madrid: Biblioteca Nueva.

Townson, N. (2009). España en cambio: el segundo franquismo (1959-1975). Madrid: Siglo XXI.

Valls, M. (1964). "Noticia de la I Bienal de Música Contemporánea". La Vanguardia, 11 de diciembre, p. 29.

Fecha de recepción: 08/11/2017

Fecha de aceptación: 04/12/2017 